\title{
Discordance between MRI and echocardiography in the assessment of mitral regurgitation severity: prediction of surgical response suggests mri may be more accurate
}

\author{
Seth Uretsky ${ }^{1 *}$, Edgar Argulian², Sai Priyanka Gudiwada ${ }^{2}$, Randy Cohen², James Jang ${ }^{3}$, Farooq A Chaudhry ${ }^{5}$,
} Leo Marcoff ${ }^{1}$, Konstantinos Koulogiannis ${ }^{1}$, Linda D Gillam', Steven Wolff ${ }^{4}$

From 18th Annual SCMR Scientific Sessions

Nice, France. 4-7 February 2015

\section{Background}

The assessment of mitral regurgitation (MR) severity is often based on echocardiographic criteria and clinical assessment. MRI can also quantify MR severity, indirectly as the difference between left ventricular (LV) stroke volume and forward flow. In clinical practice these imaging modalities can be discordant. The purpose of this prospective, multicenter trial is to compare the two techniques in assessing the severity of MR.

\section{Methods}

To date, this IRB approved trial includes 103 patients (61 \pm 14 yrs, male 57\%) with MR (19 functional, 49 degenerative, 35 other). All patients had 2D transthoracic echocardiography (Echo) and 39 (38\%) patients had a transesophageal Echo. The studies were generally complete and allowed for both a qualitative and quantitative assessment of mitral regurgitant severity by experienced echocardiographers blinded to the MRI. Using the integrated approach advocated by the American Society of Echocardiography, mitral regurgitant severity was qualitatively characterized as mild, moderate, or severe. In addition, echocardiographic regurgitant volume was quantified by PISA. The same patients underwent MRI to determine MR regurgitant severity, which was calculated as the difference between LV stroke volume and forward flow. LV stroke volume was determined from short axis cine images. Phase-contrast images of the great vessels were used to determine

${ }^{1}$ Cardiovascular Medicine, Morristown Medical Center, Morristown, NJ, USA Full list of author information is available at the end of the article forward flow. MR severity was categorized as mild $<30$ $\mathrm{ml}$, moderate $30-59 \mathrm{ml}$, or severe $\geq 60 \mathrm{ml}$. A subset of 33 patients (10 mitral valve replacement, 23 repair) had isolated mitral valve surgery, of which 25 returned for a follow-up MRI after 4-6 months. For Echo and MRI, the presurgical MR regurgitant volume was correlated with the postoperative decrease in LV end-diastolic volume (EDV).

\section{Results}

Agreement was poor $(37 / 103=36 \%$, Table) between MRI and the integrated echocardiographic approach to assessing MR severity. Discordance between MRI and Echo was sometimes striking. For example, of the 58 patients that were thought to have severe MR on Echo, 34\% were determined to have mild MR by MRI. Similarly poor comparative results were obtained when using purely quantitative Echo parameters such as PISA to quantify regurgitant volume $\left(\mathrm{r}^{2}=0.3, \mathrm{p}<0.001\right)$. In the 25 patients that were referred for isolated mitral valve surgery and who returned for follow-up MRI, there was

Table 1 Comparison of Mitral Regurgitation Severity by MRI and Echocardiography

\begin{tabular}{ccccc}
\hline & & \multicolumn{3}{c}{ MRI } \\
\hline Echo & Mild & 14 & Moderate & Severe \\
\hline & Moderate & 19 & 0 & 0 \\
\hline & Severe & 20 & 25 & 2 \\
\hline
\end{tabular}



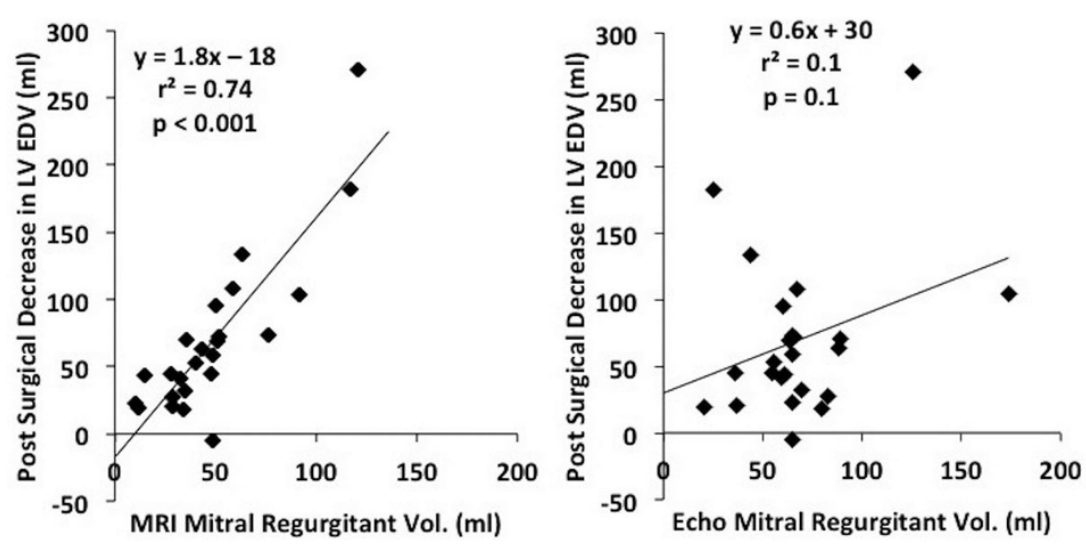

Figure 1 Correlation between mitral regurgitant volume qauntified by MRI and Echo and the post-surgical decrease in LV EDV.

a good correlation between MRI regurgitant volume and decrease in LV EDV $\left(\mathrm{r}^{2}=0.74, \mathrm{p}<0.001\right.$, Figure). There was no significant correlation between Echo regurgitant volume and decrease in $\operatorname{LV} \operatorname{EDV}\left(\mathrm{r}^{2}=0.1, \mathrm{p}-0.1\right.$, Figure).

\section{Conclusions}

MRI and echocardiography have only a modest correlation in the assessment of MR severity. The strong correlation between MR severity and post surgical remodeling suggests that MRI is the more accurate test.

\section{Authors' details}

${ }^{1}$ Cardiovascular Medicine, Morristown Medical Center, Morristown, NJ, USA.

${ }^{2}$ St. Luke's and Roosevelt Hospitals, New York, NY, USA. ${ }^{3}$ Department of Medicine, San Jose Medical Center, San Jose, CA, USA. ${ }^{4}$ Carnegie Hill Radiology, New York, NY, USA. ${ }^{5}$ Cardiovascular Medicine, Mount Sinai School of Medicine, NY, USA.

Published: 3 February 2015

doi:10.1186/1532-429X-17-S1-P262

Cite this article as: Uretsky et al:: Discordance between MRI and echocardiography in the assessment of mitral regurgitation severity: prediction of surgical response suggests mri may be more accurate Journal of Cardiovascular Magnetic Resonance 2015 17(Suppl 1):P262.
Submit your next manuscript to BioMed Central and take full advantage of:

- Convenient online submission

- Thorough peer review

- No space constraints or color figure charges

- Immediate publication on acceptance

- Inclusion in PubMed, CAS, Scopus and Google Scholar

- Research which is freely available for redistribution 